\title{
Shear modulus loss as damage indicator of structural integrity in bonded joints
}

\author{
José de Jesús Villalobos-Luna, Rodrigo Salazar-Colunga, Pedro Lopez-Cruz, \\ Moises Hinojosa Rivera \\ Universidad Autónoma de Nuevo León \\ Facultad de Ingeniería Mecánica y Eléctrica \\ jose.villalobosln@uanl.edu.mx, rodrigo.salazarco@uanl.edu.mx, pedro.lopezcr@uanl.edu.mx, \\ hinojosa@fime.uanl.mx
}

\begin{abstract}
Damage in single lap joints under shear load was assessed. Specimens were tested in accordance with ASTM D1002-10(2019). Controls were taken on adhesive and surface preparation, adhesive thickness, and load-specimen alignment. Digital Image Correlation was used to measure stresses over the adhesive, and shear modulus variation and percent of damage were assessed. Results show shear modulus losses against shear stress. Finally, early damage evolution was determined up to $10 \%$ of the shear load rate and later, increasing up to 70\%-96\%.
\end{abstract}

\section{KEYWORDS}

Bonded joints, Shear Modulus Loss, Digital Image Correlation, Damage Assessment, Structural Integrity.

\section{RESUMEN}

Se evaluó el daño en uniones de traslape simple bajo carga cortante. Las muestras se probaron de acuerdo con la norma ASTM D1002-10(2019). Se controló la preparación de la superficie, el espesor del adhesivo y alineación de la carga. La correlación digital de imágenes se utilizó para medir los esfuerzos sobre el adhesivo y se evaluó la variación del módulo de corte y el porcentaje de daño. Los resultados muestran pérdidas en el módulo de corte en función del esfuerzo cortante. Finalmente, se determinó la evolución temprana del daño hasta un $10 \%$ de cortante, e incrementando hasta alcanzar el $70 \%-96 \%$.

\section{KEYWORDS}

Uniones Adhesivas, Pérdida del Módulo de Corte, Correlación Digital de Imágenes Evaluación del Daño, Integridad Estructural.

\section{INTRODUCTION}

Fracture mechanics is an important part and logic result of the field of strength of materials. Early work on the strength of materials focused first on basic properties and later, as the theories of elasticity and plasticity evolved to include structures with flaws were developed, on the strength of structures components containing stress concentrators. Fracture mechanics deals with the strengths of materials and structures which contain flaws in the form of detectable or visible sharp cracks. 
The fundamental concept of damage has several meanings according to the context and application; however, Worden et al. ${ }^{1}$ described the concepts of failure, damage, and defect in a hierarchical form as described below.

Failure. It is when a structure cannot operate satisfactorily.

Damage. It is when the structure no longer operates in ideal conditions, but can operate in satisfactory conditions, but in a sub-optimal way.

Defect. It is inherent in the material and statistically all materials will contain a known number of defects. This means that the structure will operate optimally even if the constituent materials contain defects.

Therefore, the main objective of a damage theory is to allow prediction of lifetime of the structure. Then the remaining life concept is a natural way to define damage. Damage is the center of the study of the Continuum Damage Mechanics (CDM) addresses among others the study of the growth of micro-cracks and micro-voids (and other defects) and their effect on the mechanical behavior of the material. Further consideration is the direct effect of damage on the mechanical properties of materials which result in a significant influence on the safety aspect of engineering structures.

Due to the presence of damage at the microscopic level that generates an effect on the macroscopic properties of materials or structures, several groups of researchers have proposed that a damage index can be associated with changes observed in some properties such as the change of the area of the cross section in a standardized specimen or the change in the rigidity of the structure compared to a pristine or undamaged condition.

Proposing ${ }^{2}$ several scalar damage variables. The first scalar damage variable is defined in terms of the reduction in cross sectional area, while the second scalar damage variable is defined in terms of the reduction in the elastic modulus or elastic stiffness. Based in Voyiadijis et al., ${ }^{2}$ Balieu et al. ${ }^{3}$ Lamaitre, ${ }^{4}$ and C. Basaran et al. ${ }^{5}$ the Damage Index (ID) can be determined with the scalar variable of stiffness change damage:

$$
I D=1-\frac{E}{E_{o}}
$$

Equation 1

Where $E$ is the elastic modulus of the body or structure with the presence of damage and $E_{o}$ it is the effective elastic module, in pristine condition or without failure.

Figure 1.a shows a comparison of the elastic modulus can be seen under fault conditions $E$ and the effective modulus in original conditions, pristine or without failure $E_{o}$. The elastic modulus $E$ is constant if the elasticity properties in the adhesive remains, but if there are elasticity properties variations the elastic modulus behavior must be different. Figure 1.b. shows the theoretical variation of the elastic modulus against applied stress. 
a)

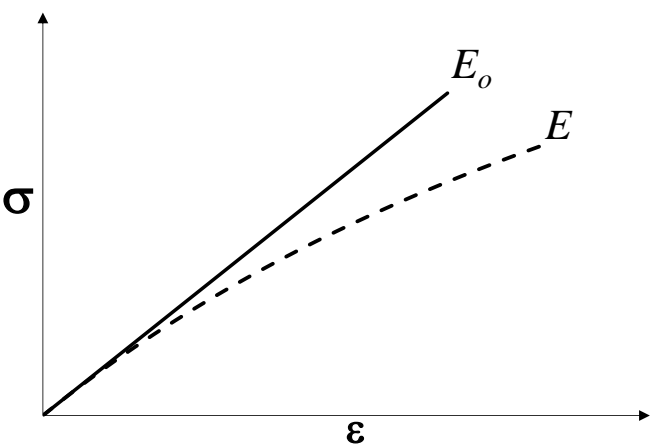

Fig. 1. a) Damaged and effective moduli of elasticity, b) Elasticity degrades against stress.

\section{ADHESIVE JOINTS DAMAGE}

One of the most important challenges of structural adhesive bonds is related to the difficult to detect the damage in advance or until the defect evolves and a "symptom" reveals its presence inside the material or structure. The study of the mechanics of damage in adhesive joints is carried out in a multidisciplinary context; however, it is an open and extensive field to research and with an impact on the strength, durability, and application of adhesive joints in high-tech structures and primary structures with high demands of mechanical performance and safety like aeronautics, space, automotive, wind energy, shipping, defense, etc.

Wahab et al. ${ }^{6}$ published the effect of many parameters for optimization and maximizing the fatigue resistance and durability of adhesive joints. These parameters were identified as geometric parameters, material parameters, surface loading and treatment conditions, and curing conditions.

In 2009 Banea et al. ${ }^{7}$ and in 2013 Krishnaraj et al. ${ }^{8}$ worked on predicting strength on joints with both adhesive and rivets. In theory, adding a rivet to the adhesive bond allows to have a predictable fault path first in the rivet acting as a mechanical fuse before the adhesive bond fails; however, this premise is not always the safest, acceptable, or certifiable. For instance, in the case of composite materials, the adhesive bond can fail before the rivet due to damage caused to the substrate and the adhesive itself generating concentrations of stresses that significantly impact the structural integrity and can significantly reduce the mechanical strength of the complete joint.

In 2015 Antunes $^{9}$ published a study about the flaws in adhesive bonds, the aim of the research was to analyze the strength and performance of the commercial epoxy adhesive 3M $9323 \mathrm{~B} / \mathrm{A}$ with dissimilar substrates using Carbon-fiber-reinforced plastic (CFRP). As a preliminary approach the interest was to create a simple and realistic procedure able to produce practical results that could be used for standard bonded model calculations. The literature review and the state of the art aimed to get perfect results, on the other hand, the objective was to find results to be implemented on the daily basis, adjusted to the imperfections made for specimen manufacture. Antunes comments that there are factors during the elasticity test methods that affects the quality of the results. The slip from grips and the air entrapped on the adhesive during mixing and spreading affects the elastic parameters and important deviation for literature was found. Since the research was focused on the adhesive's parameters assessment, a peeling test was carried out. It was found that specimen manufacturing errors, misalignment between bonded areas and the thickness control may affect the results and the failure evolution. The dissimilar substrates study there was not conclusive. 
In 2016 de Sousa et al. ${ }^{10}$ reported numerical and analytical models using the cohesive zone along with the extended finite element method to assess the damage in simple overlap adhesive joints. The analytical models were based on the Volkersen method, ${ }^{11}$ the Goland-Reissner model ${ }^{12}$ and the Hart and Smith elastic model. ${ }^{13}$

\section{SHEAR STRENGTH AND DAMAGE INDEX ON ADHESIVE JOINTS}

Bonding by adhesives is usually the most appropriate solution when it comes to joining physically dissimilar or metallurgically incompatible materials, thermoset polymers, ceramics, elastomers, very thin materials, or substrates of very small size. Adhesive bonding is generally also suitable when it comes to joining large areas or when the use of adhesives means great improvements in terms of productivity. The central component of structural adhesive joints are high-performance adhesives such as epoxy polymer resins with thermo-mechanical and viscoelastic properties.

An adhesive is a substance capable of containing at least two surfaces to bind them together in a strong and permanent way. Adhesives are chosen for their retention and bonding power. In general, they are materials that have high shear and tensile strength. The most common type of structural adhesive bonding is single lap joint (SLJ) in which the load is transferred from one substrate to another by shedding stresses in the adhesive (figure 2).

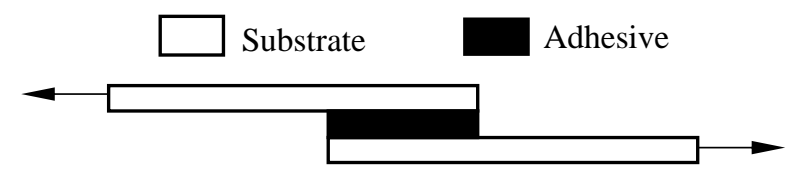

a)

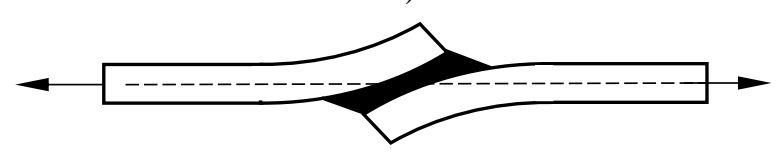

b)

Source: Figure drawed by the autor.

Fig. 2. Single overlap bonding, a) at initial load without deformation of the substrates, b) at maximum load with deformation of the substrates.

Because the applied loads are off-center in a simple overlap joint, the bending action caused by the applied load creates normal stresses (splitting stress) in the direction of the adhesive thickness. The combination of cutting stress and normal stress reduces the strength of the joint at the ends of the overlap. For the purposes of selection and characterization of adhesives, it is very common to test SLJ joints because they are easy to manufacture.

As shown in the Figure 3 there are four types of failures that may occur during an adhesive joint test: Type 1: Adhesive failure is a failure at the interface between the adherent and the adhesive.

Type 2: Cohesive failure occurs in the adhesive body, leaving part of the adhesive body on both substrates. 
Type 3: The combined failure is the one that presents partial zones with adhesive and cohesive fault in the overlap area. Substrate failure occurs when the bond between the adhesive and the substrate material is stronger than the internal strength of the substrate material. The latter type of failure is common in the adhesion of composite materials.

Type 4: In substrate failure, the original materials fail away from the joint or near the junction area when the original materials detach. Another expected failure mode is adhesive cohesion failure, in which the adhesive splits into the bonding area but remains firmly attached to both substrates. Adhesive failure, where adhesions are released from substrate materials, is considered a weak bond and is generally unacceptable.

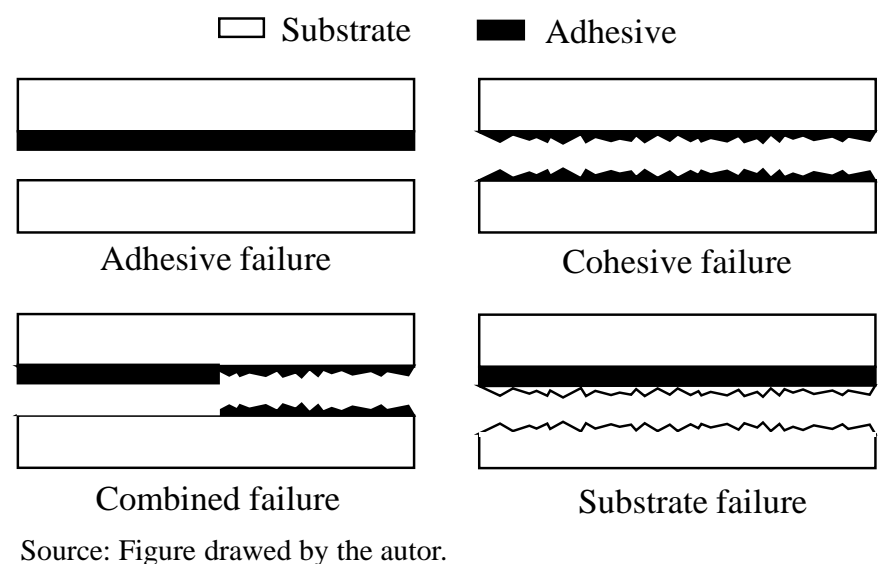

Fig. 3. Most common failure modes in adhesive testing.

An initial and simplified approach is supposed that the axial or tensile load $V$ is exerted longitudinally to one of substrates (base material to be joined) and that is converted into a uniform shear stress $\left(\tau_{\text {prom }}=V / A\right)$ through the contact area of the adhesive and subsequently again this shear stress is converted into another longitudinal force on the opposite substrate as schematized in the Figure 4.a. In fact, the substrates are not rigid and deforms closer to their final load, as shown in the Figure 4.b. Thus the shear stress generated is not uniform but grows at the ends of the overlap, as illustrated in figure 4.c.

Finally, the shear stress present in the adhesive by the off-center or non-collinear load causes a bending in a substrate. In addition to the non-uniform distribution of the shear stress, this flexion increases the transverse stresses, sometimes the well-known peeling stress (peeling) is formed, or at other times called cleavage or cleavage stress, figure 4.d.

Because of the chemical, mechanical, thermal, and viscoelastic processes involved in adhesive joints, the strength evaluated not only corresponds to the body of the adhesive, but to the effects of the substrates and bonding interfaces, which is why adhesive bonding is considered a complex system. 


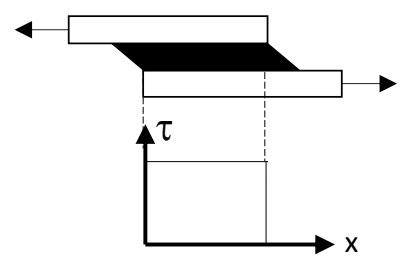

a)

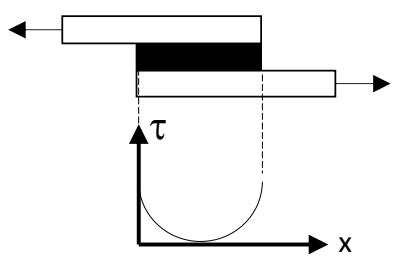

b)

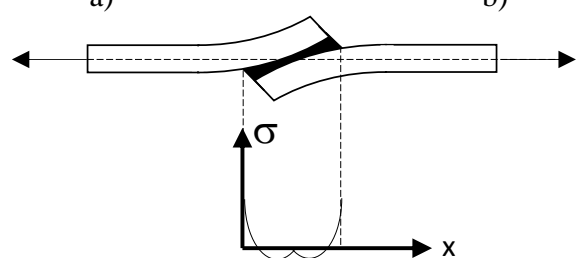

c)

Source: Figure drawed by the autor.

Fig. 4. Stress distributions in the adhesive of a single overlap joint, a) Scheme of average uniform shear stress on the adhesive, b) Scheme of non-uniform shear stress on the adhesive, c) Scheme of peeling stress on the adhesive.

An analytical solution for simplified configuration was derived by Goland and Reissner ${ }^{12}$ in 1944; however, it was not until 1989 that Bigwood and Crocombe ${ }^{14}$ developed a simplified design equation as a model corrected to the Volkersen substrate model by introducing the Poisson module.

$$
\begin{gathered}
\tau=\frac{P \omega}{2 b} \frac{\cosh (\omega x)}{\sinh \left(\frac{\omega l}{2}\right)}+\left(\frac{t_{t}-t_{b}}{t_{t}+t_{b}}\right)\left(\frac{\omega l}{2}\right)\left(\frac{\sinh (\omega x)}{\cosh \left(\frac{\omega l}{2}\right)}\right) \\
\omega=\sqrt{\frac{G}{E t_{t} t_{a}}\left(1+\frac{t_{t}}{t_{b}}\right)}
\end{gathered}
$$

Equation 3

Where $\tau$ is the shear stress on the adhesive body, $P$ is the force applied to the inner adherend, the reciprocal of $\omega$ is the shear-lag distance as a measure of how quickly the load is transferred from one adherent to the other, $x$ is the distance measured from the middle of the overlap length, $G$ is the adhesive shear module, $E$ is the elastic modulus of the substrate, $t_{a}$ is the adhesive thickness, $t_{a}$ is the thickness of above substrate, $t_{b}$ is the thickness of below substrate, $v$ is the Poisson's ratio.

Shear modulus $G$ is directly proportional to the shear stress at the adhesive body. That is the reason which changes in the shear modulus can be a measure of the damage or integrity of the joint system. Taking into account the damage assessment model based on the stiffness change proposed by BalieuLamaitre- Basaran ${ }^{3-5}$ the percentage of damage index $\left(\% I D^{\mathrm{G}}\right)$ can be determined by analogy with the stiffness loss principle for one-way shear static load with the equation: 


$$
\% I D^{G}=\left|1-\frac{G_{V}}{G_{o}}\right| \times 100
$$

Equation 4

Where $G_{V}$ is the shear module (quasi static) after increased uniaxial load and $G_{o}$ is the initial shear module in pristine condition.

\section{COUPONS MANUFACTURING}

The strength of adhesive bond specimens is sensitive to the repeatability in the manufacturing process and variability of some of the properties such as adhesive thickness, overlap length, surface preparation, adhesive mixing properties and proportions, adhesive application and curing.

Due to the last, a specimen manufacturing process was established based on ASTM D1002-10 Standard Test Method for Apparent Shear Strength of Single-Lap-Joint Adhesively Bonded Metal Specimens by Tension Loading (Metal-to-Metal), adhesive manufacturer recommendations. ${ }^{15,16,17}$ A special steel mold was manufactured to have repeatability and accuracy at the specimen geometry, reliability and parameter deviation control like adhesive preparation and application, wetting, uniform pressure, adhesive thickness, overlapping area, geometry, uniform heat treatment and easy demolding and cleaning previously to the test. Figure 5 shows the special mold, and the final SLJ specimens. There was manufactured 20 SLJ specimens and tested at quasistatic conditions.
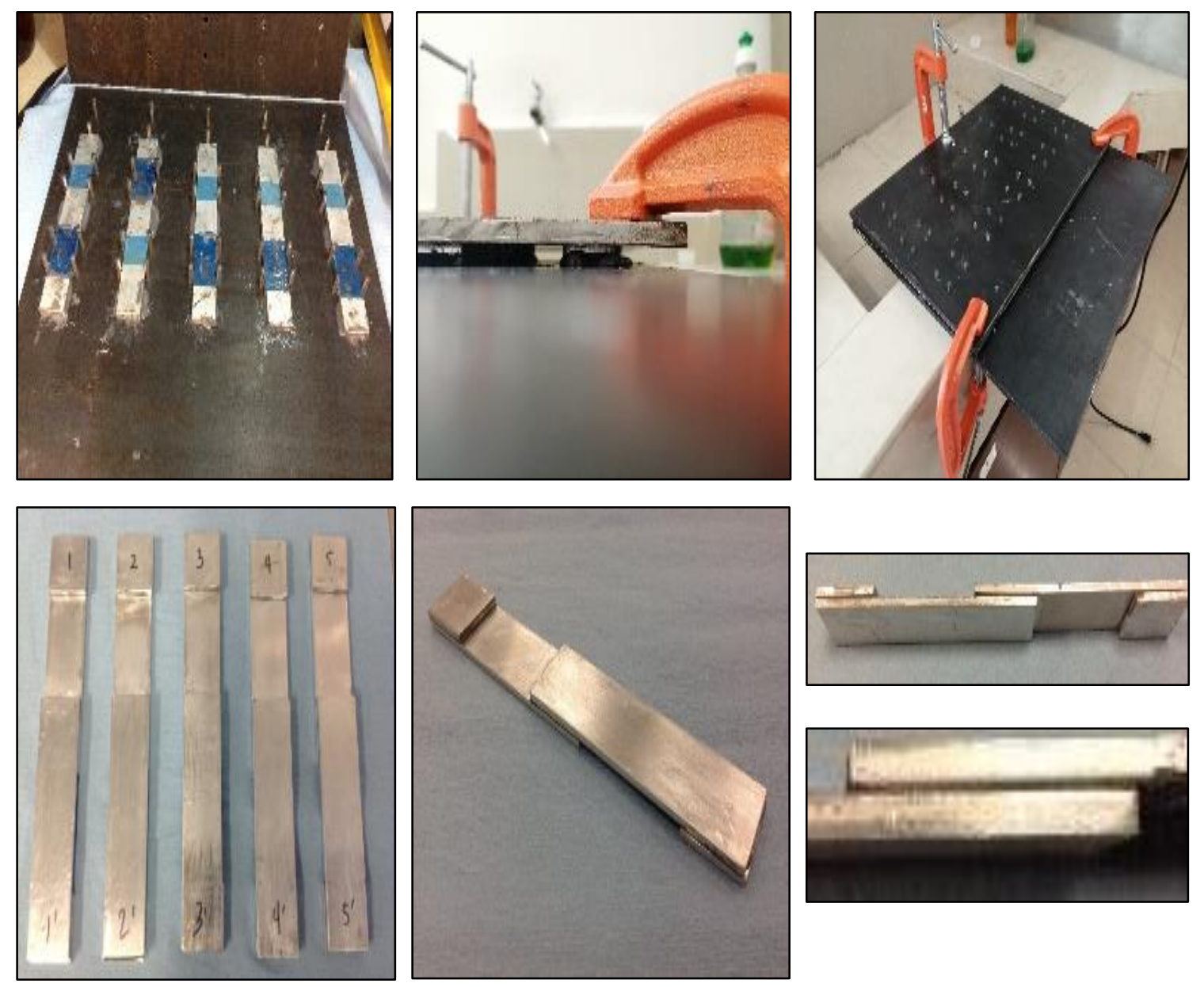

Fig. 5. Special steel mold design, manual grips for uniform pressure and final SLJ specimens. 


\section{SETUP FOR SHEAR STRESS MEASUREMENTS IN ADHESIVE JOINTS}

To perform an assessment of damage in an adhesive joint the experimental setup of Quasi-static unidirectional shear condition or QSSC was established.

Quasi-static unidirectional shear. A Shimadzu AGS-X universal machine was used to carried out the traction cutting test of the single overlap joint specimens with reference to ASTM D1002-10 Standard Test Method for Apparent Shear Strength of Single-Lap-Joint Adhesively Bonded Metal Specimens by Tension Loading (Metal-to-Metal) (figure 6). A quasi-static load was applied with a speed of 1,270 $\mathrm{mm} / \mathrm{min}$ for a maximum load range of $10,000 \mathrm{~N}$. Simultaneously, the Digital Image Correlation Technique was applied mapping the shear strain near the border between the adhesion zone to capture the deformations between the adhesive and adherent and getting in the post-processing stage the shear stress-strain curve $(\tau-\gamma)$ and the shear modulus $(G, M P a)$ in "without damage" or "pristine" condition.

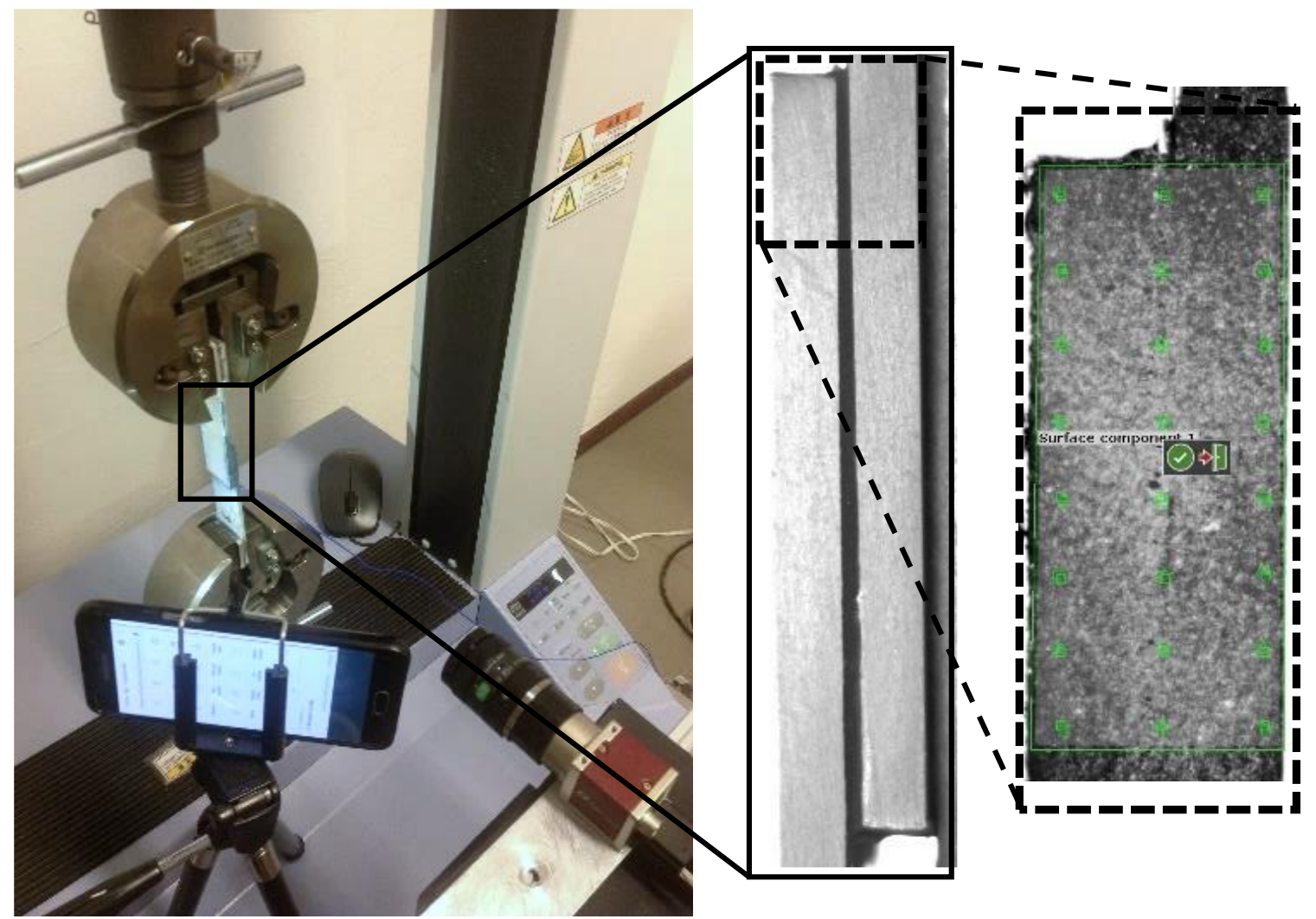

Fig. 6. Experimental setup for the SLJ test under quasi-static shear load (left), zoom at the lapping zone (center) and the measure area dashed by a contrast background needed by the DIC technique (right).

Digital Image Correlation. A high-resolution camera Allied Vision, Model Mako U503-B with 5 megapixels was used along with a $50 \mathrm{~mm}$ lens and extension tubes. Due to the high magnification and achieving a high accuracy approach, a support mounted on remote-controlled linear guides was used, with small linear displacements for each servomotor revolution. The configuration achieved a total of 940 pixels over the width of the joint, i.e. a resolution of $0.0072 \mathrm{~mm} /$ pixel, enough to accurately measure both deformations and displacements. 
The measurement area of the adhesive joint with a width of $6.8 \mathrm{~mm}$, with the dark contrast pattern and bright random spotting which allows to obtain the deformation and displacement vectors in the subspace that is selected for analysis. In addition, the resolution measured between the two reference points indicated as point 1 and 2, which is 940.93 pixels $/ 6.8 \mathrm{~mm}$, i.e. 138 pixels $/ \mathrm{mm}$, is displayed. The cameras were connected to a Dell Precision 3510 Workstation for sequential image capture and synchronized with the data acquisition rate of the $10 \mathrm{kN}$ Shimadzu AGX-10 universal machine. Frame rate image acquisition was programmed to 1 image per second for static testing. In a complete case, the camera was synchronized at a speed of 5 images per second to capture a complete static test sequence.

\section{EXPERIMENTAL RESULTS}

There is a huge amount of information derived from the experimentation, that's because we present the results for one specimen only. The average results of the L3M57140N specimen are shown in figure 7 where the average maximum shear stress is $\tau_{\max \text { prom }}=9.32 \pm 2.86 \mathrm{MPa}$ and the average maximum shear strain is $\gamma_{\text {max }}$ prom $=0.07 \pm 0.02 \mathrm{rad}$.

The average stress-strain shear curve does not have a linear or proportional zone as in other materials, so the literature suggests that the yield shear stress and therefore the shear modulus can be obtained by the offset yield method ${ }^{18,19}$ or by the method of the derivatives of the stress-strain shear curve. ${ }^{20}$ $\tau_{a v}=4.12 \mathrm{MPa}$ for and $\gamma_{a v}=0.01 \mathrm{rad}$, so the shear modulus is $G_{a v}$ prom $G=343.17 \mathrm{MPa}$.

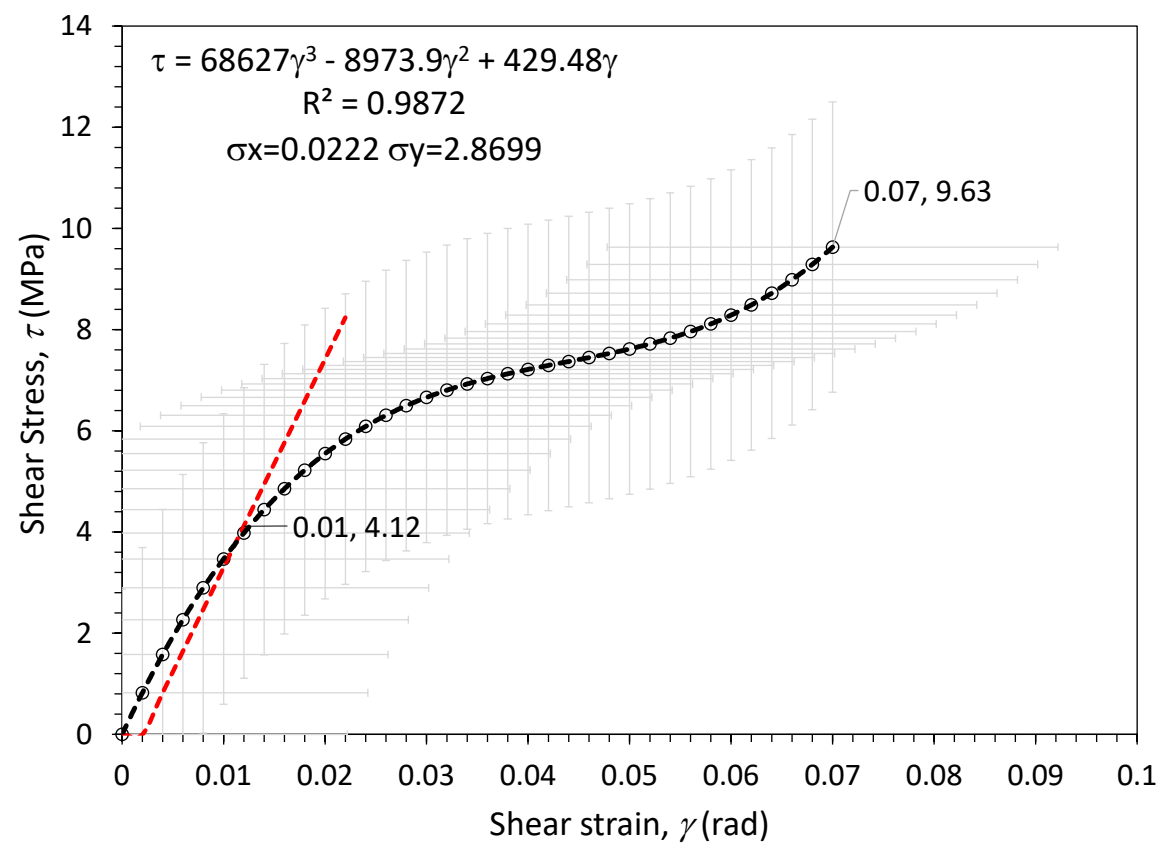

Fig. 7. Average curve for the 4 points of the adhesion line (at 1, 2, 3 and $4 \mathrm{~mm}$ ).

Figure 8 shows the change behavior of the shear modulus $G$ vs shear stress $t$ obtained by the derivative method for the shear stress-strain curve. It is observed that as the adhesive is stressed, the shear module shows a tendency to decrease, i.e. that the shear modulus suffers a degradation or a loss of stiffness in the adhesive. 


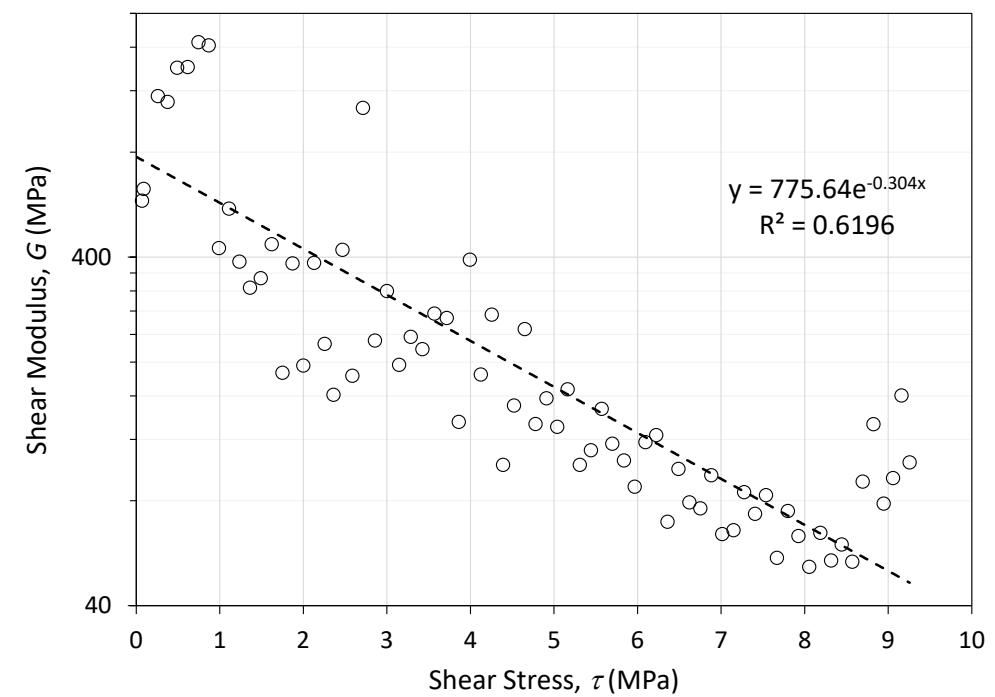

Fig. 8. Variation of the shear modulus $G$ with respect to the average shear strain.

Figure 9 shows the percentage of damage rate based on the change of the quasi-static shear modulus $\% I D^{G}$, obtained from the digital correlation measurements of images and the derivative of the curve L5M4205KN. The figure shows that the percentage of damage rate $\% I D^{G}$ is increased to $75.2 \%$ for a slight increase or load ratio $r_{V}$ of 0.01 in quasi-static condition. Subsequently, the $\% I D^{G}$ decreases to $29.2 \%$ for load ratio $r_{V}$ of 0.08 . After that, the $\% I D^{G}$ is greatly increased up to $81.8 \%$, to remain at values around $97 \%$ until the final failure.

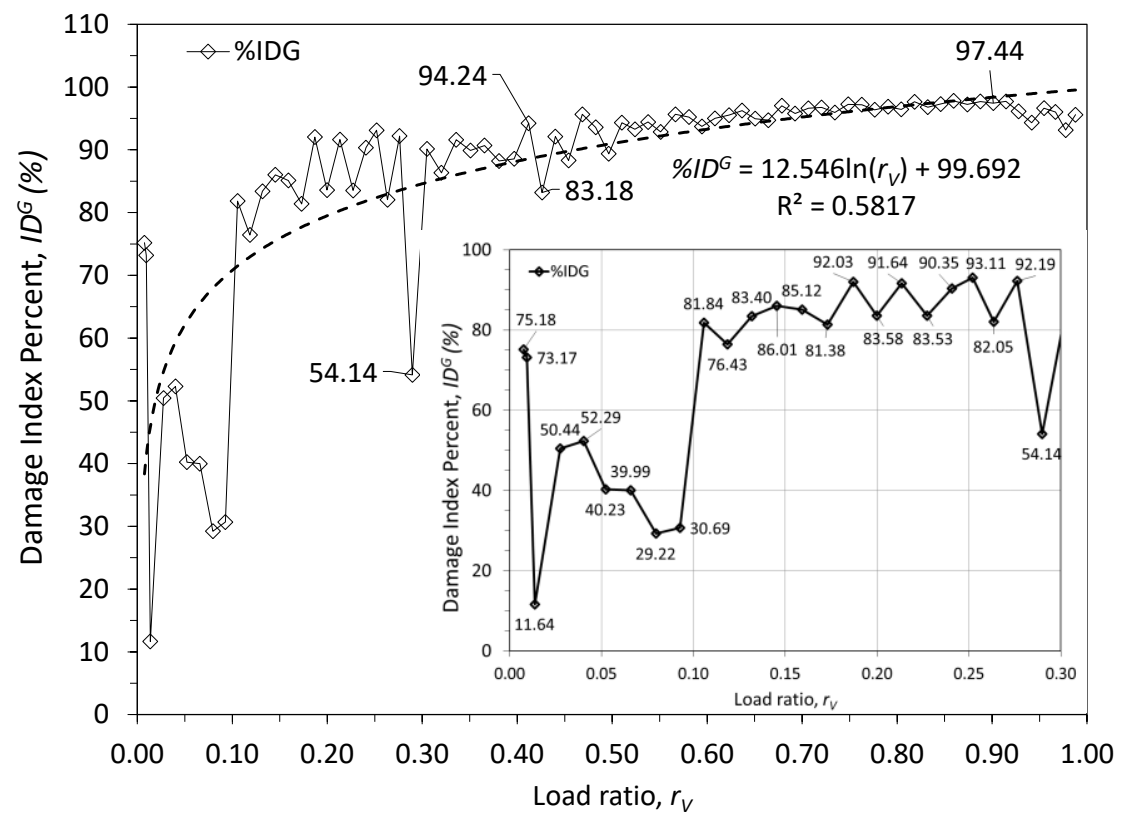

Fig. 9. Percent damage rate based on changes in the quasi-static shear modulus $I D^{G}(\%)$ vs the load ratio, $r_{V}$. 


\section{DISCUSSION}

As mentioned by Wahab, " ${ }^{6}$ There are difficulties associated with modeling the nucleation of a crack and the ability to control and detect the initiation phase". However, in this work, it was possible with unexpensive tools and precise technical references have repeatability and accuracy at the specimen geometry, reliability and parameter deviation control like adhesive preparation and application, wetting, uniform pressure, adhesive thickness, overlapping area, geometry, and uniform heat treatment for the adhesive curing.

In the other hand, we can probe that shear modulus evolves against time according with the application of quasi-static load rate. This effect is identified as the Loss Stiffens or Shear Modulus Loss and its derivative respecting time is a possible signal of damage evolve and it can be assessed in function of time, with the shear load rate or even the shear strain rate. This behavior has been stablished at the literature even for numerical methods as the elasticity bi-lineal model, however there is not many results of its variations with adhesives and shear loading conditions.

It was found that the quasi-static shear modulus $G$ has a nonlinear variation, reaching a maximum level within the first $10 \%$ of the shear stress range and progressively decreases as the stress and strain level increases. This behavior was observed for all the points analyzed on the adhesion line.

Last may be due to the viscoelastic behavior of the epoxy adhesive as a polymeric resin the shear modulus behavior can be interpreted as a degradation of the quasi-static elastic properties of the adhesive because internal molecular chains acquire a forced resorting in the direction of the shear load. These polymeric chains alignment tends to remain in time because degrees of freedom of adjacent molecules have been modified and therefore exhibit non-elastic behavior. The degradation of the quasi-static shear modulus is directly related to the viscoelastic creep and relaxation phenomena and these in turn the thermo-elastic properties of the adhesive.

Regarding the percentage of damage rate $\left(\% I D^{G}\right)$ based on the variation of the shear modulus shows a nonlinear behavior close to a logarithmic function of the form $y=A+B \ln (x)$ where $A$ and $B$ can be calculated through the method of least squares. This percent index of damage $(\% I D=A+$ $\left.B \ln \left(r_{V}\right)\right)$ is proposed as a predictive model of damage because can provide early information about damage evolution under quasi-static load for the adhesive at the single lap joint.

\section{CONCLUSION}

It is possible to assess with high accuracy and reliability the evolve of damage in SLJ under shear load, but more measures should be performed to reduce uncertainties derived from materials properties, preparation process, human manipulation vias, postprocessing procedures, etc.

A different joint configuration should be tested with another physical conditions like variations at the load speed, types of loads (cyclic, impact, random) and different environmental conditions. When all these conditions have been analyzed the following steps should be testing real parts and components like aerospace or automotive components and after that testing with structures at scale and with real dimensions. The experimentation using large scale components using design of experiments could be expensive, that is why it is very important the continuous research in this field using coupon level samples.

Techniques like Digital Image Correlation can provide a lot of information that can be used to validate theoretical models and computational algorithms about damage progress. DIC have its enough research field, however, is a powerful help to visualize the strain-stress distribution in a body. 
Finally theoretical models can be fitted as a possible average behavior of the damage inside the adhesive body during the shear load application. This is a little step focused to know the early damage stages evolution and understand the hidden behaviors or phenomena that can primarily affect the adhesive joint both strength and safety, after affect components and finally a compromise a safety application.

\section{ACKNOWLEDGMENT}

Thanks to the PAICYT 2021 program of the UANL for financing part of this project.

\section{REFERENCIAS}

1. K. Worden y J. M. Dulieu-Barton, «An Overview of Intelligent Fault Detection in Systems and Structures,» Journal of Structural Health Monitoring, vol. 3, n 1, pp. 85-98, 2004.

2. G. Z. Voyiadjis, P. I. Kattan y M. A. Yousef, «Section I Continuum Damage Mechanics Fundamentals,» de Handbook of Damage Mechanics, vol. I, New York, Springer, 2015, pp. $1-42$.

3. R. Balieu, F. Lauro, B. Bennani, G. Haugou, F. Chaari, T. Matsumoto y E. Mottola, «Damage at high strain rates in semi-crystalline polymers,» International Journal of Impact Engineering, pp. 1-8, 2015.

4. J. Lemaitre, «A Continuous Damage Mechanics Model for Ductile Fracture,» Journal of Engineering Materials and Technology, vol. 107, pp. 84-89, 1985.

5. C. Basaran, S. Nie, J. Gomez, E. Gunel, S. Li, M. Lin, H. Tang, C. Yan, W. Yao y H. Ye, «23. Thermodynamics Theory for Damage Evolution in Solids,» de Handbook of Damage Mechanics, Nano to Macro Scale for Materials, New York, Springer Science+Business Media, 2015, pp. 721-762.

6. M. M. A. Wahab, «Fatigue in Adhesively Bonded Joints: A Review,» ISRN Materials Science, vol. 2012, 2012.

7. M. Banea y L. F. M. da Silva, «Adhesively bonded joints in composite materials: an overviwe,» Part L: J. Materials: Design and Applications, vol. 223, 2009.

8. V. Krishnaraj, R. Zitoune y J. P. Davim, Drilling of Polymer-Matrix Composites, Springer, 2013.

9. D. M. Antunes, «Understanding failure of adhesively bonded joints,» pp. 1-10, 2015.

10. C. de Sousa, R. Campilho, E. Marques, M. Costa y L. da Silva, «Overview of different strength prediction techniques for single-lap bonded joints,» Journal of Materials: Design and Applications, vol. 231, $\mathrm{n}^{\mathrm{o}}$ 1-2, pp. 210-223, 2016.

11. O. Volkersen, «Die Niektraftverteilung in Zugbeanspruchten mit Konstanten Laschenquerschritten,» Luftfahrtforschung, vol. 15, pp. 41-47, 1938.

12. M. Goland y E. Reissner, «The Stresses in Cemented Joints,» Journal of Applied Mechanics, vol. 11, pp. A17-A27, 1944.

13. L. J. Hart-Smith, «Adhesive-Bonded Single-Lap Joints,» Douglas Aircraft Co., NASA Langley Report CR 112236., 1973.

14. D. Bigwood y A. Crocombe, «Elastic analysis and engineering design formulae for bonded joints,» International Journal of Adhesion and Adhesives, pp. 229-242, 1989. 
15. ASTM International, ASTM D2651-01(2016), Standard Guide for Preparation of Metal Surfaces for Adhesive Bonding, West Conshohocken, PA 19428-2959. United States: ASTM International, 2016.

16. P. Walker y W. H. Tarn, Handbook of Metal Etchants, Boca Raton, Fl: CRC Press, 1991.

17. ASTM International, ASTM D1002-10 Standard Test Method for Apparent Shear Strength of Single-Lap-Joint Adhesively Bonded Metal Specimens by Tension Loading (Metal-to-Metal), West Conshohocken, PA 19428-2959. United States: ASTM International, 2010.

18. A. Lenwari, P. Albrecht y M. Albrecht, «SED Method of Measuring Yield Strength of Adhesives and Other Materials,» Journal of ASTM International, vol. 2, nº 10, pp. 1-18, 2005.

19. ASTM International, ASTM D638-14, Standard Test Method for Tensile Properties of Plastics, West Conshohocken, PA: ASTM International, 2014.

20. R. M. Christensen, «Observations on the Determination of Yield Stress,» Acta Mechanica, vol. 196, pp. 239-244, 2008. 